\title{
Linseed oil in the maternal diet increases long chain-PUFA status of the foetus and the newborn during the suckling period in pigs
}

\author{
Francine de Quelen ${ }^{1,2,3}$, Gaëlle Boudry ${ }^{1,2 *}$ and Jacques Mourot ${ }^{1,2}$ \\ ${ }^{1}$ INRA, UMR 1079, SENAH, F-35000 Rennes, France \\ ${ }^{2}$ Agrocampus Rennes, UMR 1079, SENAH, F-35000 Rennes, France \\ ${ }^{3}$ Valorex, F-35210 Combourtillé, France \\ (Received 6 October 2009 - Revised 9 February 2010 - Accepted 10 February 2010 - First published online 23 March 2010)
}

Linseed oil, being rich in $18: 3 n-3$, represents an alternative source of $n-3$ PUFA in the maternal diet. However, little is known about the effect of this oil on the long chain $n$-3 PUFA composition of offspring, which are required for normal growth and maturation of numerous organs. The main objective of the experiment was therefore to investigate fatty acid composition of tissues from sows at the end of gestation and from piglets during the first week of postnatal life in response to maternal dietary linseed oil intake. Sows received either a lard (LAR)-based diet or a linseed oil (LSO)-based diet during gestation and lactation. Fatty acid composition was evaluated in sow plasma, placenta and milk, and in different tissues of piglets on days $0,3,7,21$ and 32 . The LSO diet increased the proportions of $n$-3 PUFA and especially $22: 6 n-3$ in the placenta. The carcass of LSO piglets at birth contained greater proportions of 20:5n-3, 22:5n-3 and $22: 6 n-3$. The LSO sow milk exhibited greater proportions of $18: 3 n-3$ compared with the LAR sow milk. The piglets suckling LSO sows had greater proportions of $18: 3 n-3,20: 5 n-3$ and $22: 5 n-3$ in plasma and carcass. The proportions of $22: 5 n-3$ and $22: 6 n-3$ were greater in the brain of LSO piglets than in that of LAR piglets during the suckling period. In conclusion, LSO in the maternal diet during gestation and lactation increases $22: 6 n-3$ concentrations in the placenta and in the foetus carcass, and it maintains $22: 6 n-3$ concentrations in the brain during the first week of postnatal life.

n-3 PUFA: Maternal diet: Neonate: Fatty acid composition: Linseed

The PUFA composition of the maternal diet during gestation and lactation can affect the composition of the foetus and the neonate (through the maternal milk) ${ }^{(1,2)}$ and, consequently, modulate the development of physiological functions. Indeed, PUFA, including $n-6$ and $n-3$ PUFA, are essential components in the cells of all tissues, and are required for normal growth and maturation of numerous organ systems in newborns.

$\alpha$-Linolenic acid (18:3n-3) and linoleic acid (18:2n-6) are the precursors of the $n-3$ and $n-6$ PUFA families, respectively. The metabolism of $18: 3 n-3$ and $18: 2 n-6$ by desaturation and elongation leads to a series of long-chain PUFA (LC-PUFA) including eicosapentaenoic acid (20:5n-3), docosapentaenoic acid (22:5n-3) and DHA (22:6n-3) of the $n-3$ family, and arachidonic acid $(20: 4 n-6)$ of the $n-6$ family ${ }^{(3,4)}$. These precursors cannot be synthesised by animals. Precursors and/ or LC-PUFA must therefore be supplied in the diet or through placental transport during foetal life. The $n-6$ to $n-3$ PUFA ratio in the diet is crucial because of enzymatic competition between $18: 2 n-6$ and $18: 3 n-3$ for elongation and desaturation into LC-PUFA. An inadequate $n-6$ to $n-3$ PUFA ratio may lead to an imbalance in the concentrations of $n-6$ LC-PUFA and $n$-3 LC-PUFA, and it may have consequences for the development of physiological functions. Neuringer et al. ${ }^{(5)}$ showed that rhesus monkeys deprived of dietary n-3 PUFA during the prenatal and postnatal periods developed visual impairment. Moreover, an epidemiological study suggested that a high $18: 2 n-6$ status of newborns at high risk of atopy was linked to allergy sensitivity ${ }^{(6)}$.

In Western populations, over the last 40 years, pregnant and lactating women have been consuming high levels of $n-6$ PUFA, resulting in a high $n-6$ to $n-3$ PUFA ratio in their milk $^{(7)}$. Actual recommendations are to balance the $n-6$ to $n-3$ PUFA ratio in the maternal diet by decreasing the consumption of $n-6$ PUFA and/or by increasing that of $n-3$ PUFA. For example, the Agence Française de Sécurité Sanitaire des Aliments suggests dietary intakes of $2 \mathrm{~g} / \mathrm{d}$ of $18: 3 n-3$ and $10 \mathrm{~g} / \mathrm{d}$ of $18: 2 n-6$ for pregnant and lactating women. The main sources of $n$-3 PUFA currently consumed are marine sources such as mackerel rich in 20:5n-3 $(1.8 \mathrm{~g} / 100 \mathrm{~g}$ of fish flesh) and $22: 6 n-3(1.2 \mathrm{~g} / 100 \mathrm{~g}$ of fish flesh). Some vegetable oils, such as linseed oil (LSO) or walnut oil, are rich in $18: 3 n-3(56-71$ and $9-15 \%$ of total fatty acids, respectively), and they could be used to diversify $n$-3 PUFA dietary sources. However, the capacity of adults to convert $18: 3 n-3$ into $20: 5 n-3$ or $22: 6 n-3$ is very limited ${ }^{(8,9)}$, although some data suggest that this capacity increases during

Abbreviations: LAR, lard; LC-PUFA, long-chain PUFA; LSO, linseed oil.

* Corresponding author: Dr Gaëlle Boudry, fax +3302 234850 80, email gaelle.boudry@ rennes.inra.fr 
gestation $^{(10,11)}$. Some studies have already investigated the effect of a maternal $18: 3 n$-3-rich diet on newborn fatty acid composition. For example, Bazinet et al. ${ }^{(12)}$ showed that piglets suckling sows consuming an 18:3n-3-rich diet had $54 \%$ more $22: 6 n-3$ in their liver and $24 \%$ more $22: 6 n-3$ in their brain than control piglets at $14 \mathrm{~d}$ of age. Farmer \& Petit $^{(13)}$ also demonstrated that a maternal $18: 3 n$-3-rich diet increased the percentage of $22: 6 n-3$ (1.2 times more than control) in piglet brain at $1 \mathrm{~d}$ of age. Moreover, supplementation of the maternal diet with LSO slightly increased the proportions of $20: 5 n-3$ and $22: 6 n-3$ in piglet plasma at birth $^{(14)}$. In parallel, in human subjects, maternal $18: 3 n-3$ supplementation during pregnancy increased the proportion of $20: 5 n-3$ by twofold in newborn plasma at birth ${ }^{(15)}$. These studies clearly confirm that $18: 3 n-3$ supplementation can increase LC-PUFA status in the newborn. However, only one time point has been studied after birth. The main objective of our experiment was to investigate, in sows and piglets, the effect of maternal LSO intake on the fatty acid composition of the sow plasma and placenta and on the fatty acid composition of different tissues of the newborn before any suckling. The effect of maternal LSO intake on the evolution of the fatty acid composition of sow milk and piglet tissues at different time points during the suckling period was also established.

\section{Materials and methods}

\section{Animals and diets}

Experiments were conducted under the guidelines of the French Ministry of Agriculture for Animal Research.
Twenty sows (Large White $\times$ Landrace, 237 (SEM 3) kg) and their piglets $(($ Large White $\times$ Landrace $) \times$ Pietrain $)$ from the experimental herd of INRA (St Gilles, France) were used.

Four diets were formulated according to the nutrient and energy needs of pregnant and lactating sows ${ }^{(16)}$. They included a standard gestation or lactation diet (Cooperl, Lamballe, France) supplied with $40 \mathrm{mg} / \mathrm{kg} \quad \alpha$-tocopherol and either lard (LAR; Charcuterie Industrielle, Mordelles, France) or LSO (Valorex, Dunkerque, France; Table 1). Sows were fed a standard gestation diet (Cooperl) until the 28th day of gestation. They were then separated into two groups: the first group received the LAR diet throughout gestation and lactation and the second group received the LSO diet throughout gestation and lactation. They were given $2 \cdot 8 \mathrm{~kg} / \mathrm{d}$ of feed during gestation corresponding to $42 \mathrm{~g} / \mathrm{d}$ of LAR or linseed and $7 \mathrm{~kg} / \mathrm{d}$ of feed during lactation corresponding to $385 \mathrm{~g} / \mathrm{d}$ of LAR or linseed. This amount of feed is slightly under the usual feeding practice for pregnant and lactating sows. The transition from 2.8 to $7 \mathrm{~kg} / \mathrm{d}$ was gradual within the first week of lactation. Sows were not fed ad libitum, but were slightly restricted to minimise feed refusals. Indeed, sows consumed all the feed that they were offered daily.

Sows were weighed every 3 weeks from day 28 of gestation until farrowing. Parturitions were not induced. Forty-eight hours after parturition, the number of piglets was adjusted to $10-12$ by removing the extra piglets from the litter. Piglets were weaned at 28 (SEM 2) d. They were weighed immediately at birth, and then weekly until weaning, and weighing was done $4 \mathrm{~d}$ after weaning for those that were killed on day 32 . At weaning, piglets that had been selected for killing on

Table 1. Composition of diets

\begin{tabular}{|c|c|c|c|c|}
\hline & \multicolumn{2}{|c|}{ LAR $(\mathrm{g} / \mathrm{kg})$} & \multicolumn{2}{|c|}{ LSO $(g / k g)$} \\
\hline & Gestation & Lactation & Gestation & Lactation \\
\hline \multicolumn{5}{|l|}{ Ingredients } \\
\hline Wheat & $221 \cdot 0$ & $227 \cdot 0$ & $221 \cdot 0$ & $227 \cdot 0$ \\
\hline Maize & $100 \cdot 0$ & $120 \cdot 0$ & $100 \cdot 0$ & $120 \cdot 0$ \\
\hline Barley & 337.0 & 254.0 & 337.0 & 254.0 \\
\hline Wheat bran & $155 \cdot 0$ & $100 \cdot 0$ & $155 \cdot 0$ & $100 \cdot 0$ \\
\hline Soyabean meal & $90 \cdot 0$ & $210 \cdot 0$ & $90 \cdot 0$ & $210 \cdot 0$ \\
\hline Sugar beet pulp & $50 \cdot 0$ & - & $50 \cdot 0$ & - \\
\hline Calcium carbonate & $19 \cdot 0$ & 11.0 & $19 \cdot 0$ & 11.0 \\
\hline Dicalcium phosphate & 3.0 & $13 \cdot 0$ & 3.0 & $13 \cdot 0$ \\
\hline $\mathrm{NaCl}$ & $5 \cdot 0$ & $5 \cdot 0$ & $5 \cdot 0$ & $5 \cdot 0$ \\
\hline Trace element and vitamin $\mathrm{mix}^{*}$ & $5 \cdot 0$ & $5 \cdot 0$ & $5 \cdot 0$ & $5 \cdot 0$ \\
\hline LSO & 0.0 & 0.0 & $15 \cdot 0$ & $55 \cdot 0$ \\
\hline LAR & $15 \cdot 0$ & $55 \cdot 0$ & 0.0 & 0.0 \\
\hline \multicolumn{5}{|c|}{ Fatty acid composition ( $\mathrm{g} / 100 \mathrm{~g}$ fatty acid) } \\
\hline SFA & $30 \cdot 0$ & $42 \cdot 0$ & $19 \cdot 1$ & $19 \cdot 5$ \\
\hline MUFA & $30 \cdot 0$ & $32 \cdot 0$ & $20 \cdot 3$ & $21 \cdot 7$ \\
\hline PUFA & $40 \cdot 0$ & $26 \cdot 0$ & $60 \cdot 6$ & $58 \cdot 8$ \\
\hline$n-6$ PUFA & $36 \cdot 0$ & $22 \cdot 1$ & $40 \cdot 7$ & 29.2 \\
\hline $18: 2 n-6$ & 35.9 & $21 \cdot 8$ & $40 \cdot 7$ & $29 \cdot 2$ \\
\hline$n-3$ PUFA & 4.0 & 2.5 & $19 \cdot 5$ & $29 \cdot 6$ \\
\hline $18: 3 n-3$ & $3 \cdot 8$ & $2 \cdot 4$ & $19 \cdot 0$ & $29 \cdot 3$ \\
\hline $20: 5 n-3$ & 0.2 & 0.1 & 0.3 & 0.1 \\
\hline$n-6$ PUFA $/ n-3$ PUFA & 8.6 & 8.8 & $2 \cdot 1$ & 1.0 \\
\hline
\end{tabular}

LAR, lard-based diet; LSO, linseed oil-based diet.

*This premix (Cooperl) supplied per $\mathrm{kg}$ of diet: retinol $3 \mathrm{mg}$, cholecalciferol $37.5 \mu \mathrm{g}, \alpha$-tocopherol $40 \mathrm{mg}$, menadione $2 \mathrm{mg}$, thiamine $2 \mathrm{mg}$, riboflavin $4 \mathrm{mg}$, niacin $20 \mathrm{mg}$, D-pantothenic acid $10 \mathrm{mg}$, pyridoxine $3 \mathrm{mg}$, D-biotin $0.2 \mathrm{mg}$, folic acid $3 \mathrm{mg}$, vitamin $\mathrm{B}_{12} 20 \mu \mathrm{g}$, choline $500 \mathrm{mg}$, Fe $80 \mathrm{mg}$ as ferrous carbonate, $\mathrm{Cu} 10 \mathrm{mg}$ as copper sulphate, Mn $40 \mathrm{mg}$ as manganese oxide, $\mathrm{Zn} 100 \mathrm{mg}$ as zinc oxide, Co $0.1 \mathrm{mg}$ as cobalt sulphate, iodine $0.6 \mathrm{mg}$ as calcium iodate and $\mathrm{Se} 0.15 \mathrm{mg}$ as sodium selenite. 
day 32 were placed in individual cages and offered a standard weaning diet (net energy $10 \cdot 6 \mathrm{MJ} / \mathrm{kg}$ and $195 \mathrm{~g}$ crude protein/ $\mathrm{kg}$ of DM; Cooperl). The amount of feed offered was adjusted to their body weight $(15 \mathrm{~g} / \mathrm{kg}$ body weight/d).

\section{Tissue collection}

Sows. At $92 \mathrm{~d}$ of gestation, blood samples were obtained by puncture of a jugular vein from each sow in heparinised tubes. After centrifugation $\left(4000 \mathrm{~g}, 10 \mathrm{~min}, 4^{\circ} \mathrm{C}\right)$, plasma was stored at $-20^{\circ} \mathrm{C}$. Just after expulsion of the placenta, three pieces (around $150 \mathrm{~g}$ each) were randomly sampled from the entire placenta. The three pieces were homogenised together using a meat grinder with a $5 \mathrm{~mm}$ diameter screen (Hobart, Paris, France). The homogenates were stored at $-20^{\circ} \mathrm{C}$. For half of the sows ( $n$ 5), colostrum samples were collected on day 0 (within $12 \mathrm{~h}$ after the onset of parturition), and milk samples were collected on days 7, 14, 21 and 28 (following the same sows throughout lactation) after oxytocin injection ( $1 \mathrm{ml}$ of a $20 \mu \mathrm{g} / \mathrm{ml}$ solution) from four randomly selected teats (4-5 $\mathrm{ml}$ per teats). Samples from the different teats were pooled and kept at $-20^{\circ} \mathrm{C}$.

Piglets. One piglet per litter was killed at birth before suckling (day 0). Since the piglets were killed just at birth before any suckling, we could not wait for the entire litter to be born to calculate the average weight of the piglets within the litter. Therefore, we selected piglets weighing between 1.2 and $1.5 \mathrm{~kg}$, corresponding to the average weight of newborn piglets in our herd over the past 10 years. Other piglets from the same litter (with birth weights and weight gain until killing close to the average weight and weight gain of the litter) were killed at days $3,7,21$ and 32 ( $4 \mathrm{~d}$ after weaning) of age. Piglets were separated from the sow (days 3, 7 and 21), or had no access to feed (day 32) $1 \mathrm{~h}$ before killing. Each piglet was killed by electronarcosis and exsanguination. At exsanguination, blood samples were collected in heparinised tubes $(5-10 \mathrm{ml})$ and centrifuged $\left(4000 \mathrm{~g}, 10 \mathrm{~min}, 4^{\circ} \mathrm{C}\right)$ within $15 \mathrm{~min}$, and plasma was stored at $-20^{\circ} \mathrm{C}$. Carcasses were frozen (without the head, the tail and the internal organs). Frozen carcasses were then minced and homogenised using a meat grinder with a $5 \mathrm{~mm}$ diameter screen (Hobart). Samples were stored at $-20^{\circ} \mathrm{C}$. Brains were dissected from the head at the time of killing, and were immediately frozen at $-20^{\circ} \mathrm{C}$. Frozen brains were then homogenised in a meat grinder with $1 \mathrm{~mm}$ diameter screen (Hobart), and the samples were stored at $-20^{\circ} \mathrm{C}$.

\section{Determination of fatty acid composition}

Lipids were extracted from the tissues of piglets from four litters by dietary group (litters randomly selected) and from five randomly selected sows by dietary group. Extractions of lipids from the placenta, brain and carcass were performed using chloroform-methanol (2:1, v/v) as described by Folch et $a l^{(17)}$. Lipids from colostrum and milk were extracted using ethyl ether-petroleum ether-ammonium (25:25:2, $\mathrm{v} / \mathrm{v} / \mathrm{v}$ ) as described by Jensen \& Clark $^{(18)}$. The lipid content of the different tissues was determined gravimetrically. Extraction of lipids from plasma was performed using the hexane-isopropanol method $(3: 2, \mathrm{v} / \mathrm{v})^{(19)}$. The lipid content of the plasma was not determined because the gravimetrical method is not sensitive enough for such low values.

Fatty acid composition was determined after transmethylation of lipids with boron trifluoride-methanol solution ${ }^{(20)}$, and was analysed on a Perkin Elmer Autosystem XL gas chromatograph equipped with a fused silica gel capillary column $(0.25 \mathrm{~mm} \times 30 \mathrm{~m} ;$ Agilent Technologies, Massy, France), with an $80 \%$ biscyanopropyl and $20 \%$ cyanopropyl stationary phase, using margaric acid (17:0) as an internal standard for fatty acid composition analysis of tissues. For analysis of fatty acid composition in milk, a mixed standard with margaric acid and pelargonic acid (9:0) was used. The chromatography conditions were as follows: temperature programme $45^{\circ} \mathrm{C}$ for $2 \mathrm{~min}$, increased to $195^{\circ} \mathrm{C}$ over $7.5 \mathrm{~min}$, held for $7 \mathrm{~min}$, then raised to $220^{\circ} \mathrm{C}$ for $2 \mathrm{~min}$ and finally increased to $240^{\circ} \mathrm{C}$ for $2 \mathrm{~min}$. The injector and detector temperatures were maintained at 220 and $280^{\circ} \mathrm{C}$, respectively. Retention times and peak areas were determined using chromatography software (Nelson Analytical, Inc., Cupertino, CA, USA). Results were expressed as proportions of the total fatty acid composition in comparison to the internal standards.

\section{Statistical analysis}

Data are expressed as mean values with their standard errors. Due to the large number of data, we concentrated the analysis on SFA, MUFA, PUFA, $n-3$ PUFA and $n-6$ PUFA proportions in the different tissues but not on the other classes of fatty acids. Data were analysed by analysis of variance using the general linear model procedure of Statistical Analysis Systems (1989). For zootechnical data, the fatty acid composition of sow plasma and placenta, ANOVA tested the maternal diet effect. For the other parameters (milk and piglet tissues from days 0 to 32), the model included the effect of litter, day of lactation (for milk) or piglet age (for piglet tissues), maternal diet and the day of lactation or piglet age $\times$ maternal diet interaction. Differences were considered significant at $P \leq 0 \cdot 05$.

\section{Results}

\section{Gestation outcomes and piglet growth}

The maternal diet had no effect on the weight gain of sows throughout gestation (0.69 (SEM 0.05) v. 0.68 (SEM $0.05) \mathrm{g} / \mathrm{d}$ ). Similarly, duration of gestation was not influenced by the diet (113.9 (SEM 0.3) v. 114.0 (SEM 0.4) d).

There were no differences in the litter size or mean birth weight of live piglets between the LAR and LSO groups (14.8 (SEM 1.3) v. 13.6 (SEM 1.4) piglets per litter and 1.65 (SEM 0.1) v. $1.61($ SEM 0.09$) \mathrm{kg})$. Average daily weight gain of piglets from birth to $7 \mathrm{~d}$ of age (0.18 (SEM 0.01) v. 0.19 $(\operatorname{SEM} 0.01) \mathrm{g} / \mathrm{d})$ and from birth to $28 \mathrm{~d}$ of age $(0.27$ (SEM $0 \cdot 01)$ v. $0.25($ SEM $0 \cdot 01) \mathrm{g} / \mathrm{d})$ was not different between the two groups.

\section{Sow plasma}

Although the proportions of both $n-3$ and $n-6$ PUFA were increased in the plasma of the LSO sows $(P<0.001$ and $P=0 \cdot 01$, respectively), the $18: 2 n-6$ to $18: 3 n-3$ ratio was 
Table 2. Total lipid content and fatty acid composition of sow plasma at $92 \mathrm{~d}$ of gestation and placenta at parturition

(Mean values with their standard errors for five sows)

\begin{tabular}{|c|c|c|c|c|c|c|c|c|}
\hline & \multicolumn{3}{|c|}{ Plasma } & & \multicolumn{3}{|c|}{ Placenta } & \\
\hline & LAR & LSO & SEM & & LAR & LSO & SEM & \\
\hline \multicolumn{9}{|c|}{ Total lipid content ( $\mathrm{g} / 100 \mathrm{~g}$ of tissue) } \\
\hline & ND & ND & & & 0.6 & 0.5 & 0.1 & \\
\hline \multicolumn{9}{|c|}{ Fatty acid composition ( $\mathrm{g} / 100 \mathrm{~g}$ of total fatty acids) } \\
\hline SFA & $26 \cdot 0$ & $20 \cdot 3$ & 0.6 & * & $32 \cdot 8$ & 33.7 & 0.9 & \\
\hline MUFA & $30 \cdot 8$ & $22 \cdot 3$ & 0.7 & * & $54 \cdot 2$ & 50.5 & 0.9 & * \\
\hline PUFA & $43 \cdot 2$ & $57 \cdot 4$ & 0.9 & * & $13 \cdot 0$ & $15 \cdot 8$ & 0.5 & * \\
\hline$n-6$ PUFA & $40 \cdot 1$ & $45 \cdot 3$ & 1.0 & * & $10 \cdot 2$ & 11.3 & 0.2 & \\
\hline $18: 2 n-6$ & 34.5 & 41.9 & $1 \cdot 3$ & * & $5 \cdot 6$ & $6 \cdot 8$ & 0.3 & * \\
\hline $20: 4 n-6$ & $5 \cdot 6$ & 3.4 & 0.6 & * & 4.5 & 4.5 & 0.2 & \\
\hline$n-3$ PUFA & $2 \cdot 9$ & $12 \cdot 0$ & 0.5 & * & 1.6 & $3 \cdot 3$ & 0.2 & * \\
\hline $18: 3 n-3$ & 1.4 & $9 \cdot 3$ & 0.7 & * & 0.1 & 0.4 & 0.1 & * \\
\hline $20: 5 n-3$ & 0.3 & 1.2 & 0.2 & * & 0.4 & 0.7 & 0.2 & * \\
\hline $22: 5 n-3$ & 0.8 & 1.0 & 0.1 & & 0.4 & 0.8 & 0.1 & * \\
\hline $22: 6 n-3$ & 0.3 & 0.3 & 0.1 & & 0.8 & 1.4 & 0.2 & * \\
\hline$n-6$ PUFA/n-3 PUFA & $13 \cdot 7$ & $3 \cdot 8$ & 0.5 & * & $6 \cdot 8$ & 3.7 & 0.4 & * \\
\hline $18: 2 n-6 / 18: 3 n-3$ & $24 \cdot 6$ & 4.6 & $2 \cdot 0$ & * & $44 \cdot 0$ & $16 \cdot 4$ & 4.5 & * \\
\hline
\end{tabular}

LAR, lard-based diet; LSO, linseed oil-based diet; ND, not determined.

${ }^{*}$ Mean values were significantly different between the two groups $(P<0.05)$.

dramatically lower in the LSO group than in the LAR group $(P<0 \cdot 001$; Table 2).

Within the $n$-3 PUFA family, the LSO diet increased the proportions of $18: 3 n-3(P<0.001)$ and $20: 5 n-3(P=0.002)$, but it had no effect on $22: 5 n-3$ and $22: 6 n-3$ proportions (Table 2). Within the $n$-6 PUFA family, the proportion of $18: 2 n-6$ was greater $(P=0 \cdot 006)$, while the proportion of $20: 4 n-6$ was lesser $(P=0.03)$ in the LSO group than in the LAR group (Table 2).

\section{Placenta}

The proportion of $n$-3 PUFA was greater in the placenta from LSO litters $(P=0 \cdot 002)$, with no difference for $n-6$ PUFA (Table 2). As a result, the $18: 2 n-6$ to $18: 3 n-3$ ratio was lower in the LSO group ( $P=0.006$; Table 2$)$.

Within the $n$-3 PUFA family, the dietary supplementation with LSO increased all the proportions of $n-3$ PUFA $(18: 3 n-3, P=0.004 ; 20: 5 n-3, P=0.03 ; 22: 5 n-3, P=0.001$ and $22: 6 n-3, P=0.01$ ) in the placenta (Table 2). The proportion of $18: 2 n-6$ was greater in the placenta of the LSO sows $(P=0.02)$, but there was no treatment effect on the proportion of $20: 4 n-6$ (Table 2).

\section{Piglet tissues at birth}

In the plasma, the proportions of $n-3$ and $n$-6 PUFA were greater in the LSO group $(P=0.04$ and 0.05 , respectively; Table 3). There was no difference in the $18: 2 n-6$ to $18: 3 n-3$ ratio between the two groups (Table 3). Proportions of $20: 5 n-3$ and $22: 6 n-3$ were greater in the plasma of the LSO piglets than in that of the LAR piglets $(P=0.02$ and 0.001 , respectively; Table 3 ). Within the $n$-6 PUFA family, the LSO diet increased the proportion of $20: 4 n-6(P=0.02)$, but it did not change that of $18: 2 n-6$ in piglet plasma (Table 3).
Proportions of $n-3$ and $n-6$ PUFA and the $18: 2 n-6$ to $18: 3 n-3$ ratio were similar in the carcasses of piglets from both the groups (Table 4). Within the $n$-3 PUFA family, the LSO diet increased the proportion of 20:5n-3 $(P<0 \cdot 001)$, $22: 5 n-3(P<0 \cdot 001)$ and $22: 6 n-3(P=0 \cdot 001)$ in the carcass (Table 4). The proportions of $n-6$ PUFA did not differ between the two groups (Table 4).

In the brain, the proportions of $n-6$ PUFA were similar between the LSO and LAR piglets at birth (Table 5). The proportion of $n$-3 PUFA was greater in the LSO group $(P=0.05$; Table 5). Within the $n$-3 PUFA family, there were no differences between the two groups for $18: 3 n-3,20: 5 n-3$ and $22: 5 n-3$. However, the proportion of $22: 6 n-3$ tended to be greater in the LSO group than in the LAR group ( $P=0 \cdot 07$; Table 5$)$.

\section{Sow colostrum and milk}

The colostrum/milk of LSO sows contained more $n$-3 PUFA than that of LAR sows (diet effect $P<0.001$; Table 6, data online). Dietary supplementation of the sow diet with LSO increased the proportions of $18: 3 n-3$ (diet effect $P<0 \cdot 001$ ), $20: 5 n-3$ (diet effect $P<0.001$ ) and $22: 5 n-3$ (diet effect $P<0.001)$ in the colostrum/milk, but it had no influence on the proportion of $22: 6 n-3$ (Table 6 , data online).

\section{Piglet plasma after birth}

The proportion of $n$-6 PUFA increased with time (age effect $P<0.001)$, but it was not different between the two groups (Table 3). While the proportion of $n-3$ PUFA did not vary with time in the LAR group, it increased in the plasma of the LSO piglets from day 7 and was greater in the LSO piglets than in the LAR piglets from day 3 (diet $\times$ age interaction $P<0.001$; Table 3 ). While the $18: 2 n-6$ to $18: 3 n-3$ ratio increased from day 0 in the plasma of the LAR piglets, it decreased from day 3 in the plasma of the LSO piglets (diet $\times$ age interaction $P<0.001$; Table 3 ). 
The plasma of the LSO piglets had greater proportions of $18: 3 n-3,20: 5 n-3$ and $22: 5 n-3$ than that of the LAR piglets (diet effect $P<0.001$ for $18: 3 n-3,20: 5 n-3$ and $22: 5 n-3$ ), and these proportions increased with age in the LSO group (diet $\times$ age interaction $P<0 \cdot 001$ for $18: 3 n-3$ and $20: 5 n-3$ and $P=0.003$ for $22: 5 n-3$; Table 3 ). The proportion of $22: 6 n-3$ was greater over the whole period in the plasma of the LSO piglets than in that of the LAR piglets (diet effect $P<0.001$ ), and decreased between days 0 and 7 in both the groups although more sharply in the LSO group (diet $\times$ age interaction $P=0.001$; Table 3). Within the $n$-6 PUFA family, the proportion of $18: 2 n-6$ in piglet plasma was similar between the two groups, and this proportion increased between days 0 and 3 in both the groups (age effect $P<0.001$; Table 3). The proportion of $20: 4 n-6$ differed between the two groups on days 0 and 32. It decreased with age in the LSO piglets, whereas it increased between days 21 and 32 in the LAR piglets (diet $\times$ age interaction $P=0.002$; Table 3).

\section{Piglet carcasses after birth}

The proportion of $n$-6 PUFA in the carcasses increased with time in both the groups (age effect $P<0.001$ ), and it was greater over the whole period in the carcass of the LSO piglets than in that of the LAR piglets (diet effect $P<0.001$; Table 4). The proportion of $n-3$ PUFA in the carcasses increased from day 3 in the LSO group, but it was not affected by time in the LAR group (diet $\times$ age interaction $P=0.004$; Table 4). As a result, the $18: 2 n-6$ to $18: 3 n-3$ ratio decreased between days 0 and 3 in both the groups (age effect $P<0.001$ ), but it was lower in the carcass of the LSO piglets (diet effect $P<0.001$; Table 4).

The proportions of $18: 3 n-3,20: 5 n-3$ and $22: 5 n-3$ in piglet carcass were greater in the LSO group than in the LAR group (diet effect $P<0.001$; Table 4). The proportion of $18: 3 n-3$ increased between birth and day 3 in the LSO group, while it was not influenced by age in the LAR group (diet $\times$ age interaction $P<0.001$ for the LSO group; Table 4). Moreover, the proportions of $20: 5 n-3$ and $22: 5 n-3$ decreased between birth and day 7 in the LAR group, and between birth and day 3 and then between days 7 and 21 in the LSO group (age effect $P<0.001$; Table 4). The carcass of LSO piglets contained a greater proportion of $22: 6 n-3$ over the whole period (diet effect $P=0.01$; Table 4). This proportion decreased with time in both the groups (age effect $P<0.001$ ), but the decrease tended to be sharper due to greater proportions of $22: 6 n-3$ at birth in the LSO group (diet $\times$ age interaction $P=0.08$; Table 4). Within the $n$-6 PUFA family, the proportion of $18: 2 n-6$ increased between days 0 and 3 in both the groups (age effect $P<0.001$ ), and it was greater in the carcass of the LSO piglets on days 7, 21 and 32 than in the carcass of the LAR piglets (diet effect $P<0.001$; Table 4). There was no difference between the two groups for the proportion of $20: 4 n-6$ (Table 4).

\section{Piglet brain after birth}

No difference was observed in the proportion of $n$-6 PUFA between the two groups. It increased from days 0 to 7 and decreased thereafter in both the groups (age effect $P<0 \cdot 001$; 
Table 4. Total lipid content and fatty acid composition of piglet carcass at $0,3,7,21$ and $32 \mathrm{~d}$ of age in the linseed oil-based diet (LSO) and lard-based diet (LAR) groups (Mean values with their standard errors for four piglets)

\begin{tabular}{|c|c|c|c|c|c|c|c|c|c|c|c|c|c|c|}
\hline & \multicolumn{5}{|c|}{ LAR } & \multicolumn{5}{|c|}{ LSO } & \multirow[b]{2}{*}{ SEM } & \multicolumn{3}{|c|}{$P$ value } \\
\hline & do & d3 & d7 & d21 & d32 & do & d3 & d7 & d21 & d32 & & Diet & Age & Diet $\times$ age \\
\hline \multicolumn{15}{|c|}{ Total lipid content ( $\mathrm{g} / 100 \mathrm{~g}$ of tissue) } \\
\hline & $1 \cdot 1$ & $3 \cdot 3$ & 9.5 & $14 \cdot 4$ & $12 \cdot 6$ & 1.5 & $4 \cdot 3$ & $6 \cdot 3$ & $13 \cdot 1$ & $12 \cdot 0$ & $0 \cdot 8$ & NS & $<0.001 \dagger$ & NS \\
\hline \multicolumn{15}{|c|}{ Fatty acid composition (g/100 g of total fatty acids) } \\
\hline SFA & $49 \cdot 0$ & 37.0 & 34.3 & $35 \cdot 6$ & $36 \cdot 8$ & $46 \cdot 7$ & $35 \cdot 0$ & $33 \cdot 7$ & $35 \cdot 7$ & $36 \cdot 8$ & $1 \cdot 1$ & NS & $<0.001 \ddagger$ & NS \\
\hline MUFA & $40 \cdot 9^{a}$ & 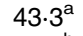 & $49.5^{\mathrm{b}}$ & $50 \cdot 8^{\mathrm{b}}$ & $49 \cdot 2^{\mathrm{b}}$ & 41.7 & $39 \cdot 0^{*}$ & $39 \cdot 6^{*}$ & $40 \cdot 0^{*}$ & $39 \cdot 7^{\star}$ & $1 \cdot 1$ & $<0.001$ & 0.002 & $<0.001$ \\
\hline PUFA & $10 \cdot 1^{a}$ & $19 \cdot 7^{b}$ & $16 \cdot 2$ & $13 \cdot 6^{\mathrm{a}}$ & $14.0^{\mathrm{a}}$ & $11 \cdot 6^{\mathrm{x}}$ & $26 \cdot 0^{y *}$ & $26 \cdot 7^{y *}$ & $24 \cdot 3^{\mathrm{y} *}$ & $23 \cdot 7^{y *}$ & 1.3 & $<0.001$ & $<0.001$ & 0.01 \\
\hline$n$-6 PUFA & $7 \cdot 2$ & $17 \cdot 1$ & $14 \cdot 1$ & $12 \cdot 0$ & $12 \cdot 3$ & 7.5 & $18 \cdot 4$ & $17 \cdot 4$ & $14 \cdot 7$ & $14 \cdot 7$ & 0.7 & $<0.001$ & $<0.001 \ddagger$ & NS \\
\hline $18: 2 n-6$ & $7 \cdot 0$ & $17 \cdot 0$ & $14 \cdot 0$ & 11.9 & $12 \cdot 2$ & $7 \cdot 4$ & $18 \cdot 3$ & $17 \cdot 3$ & $14 \cdot 7$ & $14 \cdot 6$ & 0.7 & $<0.001$ & $<0.001 \ddagger$ & NS \\
\hline $20: 4 n-6$ & 0.2 & 0.1 & 0.1 & 0.0 & 0.1 & 0.1 & 0.1 & 0.1 & 0.0 & 0.0 & 0.1 & NS & NS & NS \\
\hline$n-3$ PUFA & $2 \cdot 4$ & $2 \cdot 0$ & 1.4 & $1 \cdot 0$ & $1 \cdot 1$ & $3 \cdot 7^{x}$ & $7 \cdot 0^{y *}$ & $8 \cdot 3^{y *}$ & $9 \cdot 0^{y *}$ & $8 \cdot 3^{y *}$ & 0.8 & $<0.001$ & NS & $<0.001$ \\
\hline $18: 3 n-3$ & 0.3 & 1.0 & 1.0 & 0.8 & 0.8 & $0 \cdot 4^{x}$ & $5 \cdot 7^{7 *}$ & $7 \cdot 2^{2 *}$ & $8 \cdot 3^{z *}$ & $7 \cdot 7^{2 *}$ & 0.7 & $<0.001$ & $<0.001$ & $<0.001$ \\
\hline $20: 5 n-3$ & $0.2^{a}$ & $0.1^{\mathrm{b}}$ & $0.0^{c}$ & $0.1^{\mathrm{c}}$ & $0.1^{\mathrm{c}}$ & $0.5^{\star \star}$ & $0 \cdot 3^{y *}$ & $0.2^{\mathrm{y} *}$ & $0 \cdot 2^{2 *}$ & $0.2^{z *}$ & 0.1 & $<0.001$ & $<0.001$ & $<0.001$ \\
\hline $22: 5 n-3$ & $0.6^{a}$ & $0.5^{\mathrm{b}}$ & $0.3^{\mathrm{C}}$ & $0.2^{\mathrm{c}}$ & $0.2^{\mathrm{c}}$ & $1.0^{\mathrm{*}}$ & $0 \cdot 6^{y}$ & $0.6 y^{*}$ & $0.4^{2 *}$ & $0.4^{z}$ & 0.1 & $<0.001$ & $<0.001$ & 0.04 \\
\hline $22: 6 n-3$ & 1.3 & 0.3 & 0.1 & 0.1 & 0.1 & $1 \cdot 8^{\star}$ & 0.4 & 0.2 & $0 \cdot 1$ & 0.1 & 0.1 & 0.01 & $<0.001$ & 0.08 \\
\hline$n-6$ PUFA $/ n-3$ PUFA & $3.5^{\mathrm{a}}$ & $9.5^{\mathrm{b}}$ & $10 \cdot 4^{\mathrm{b}}$ & $11.0^{\mathrm{b}}$ & $7.4^{\mathrm{b}}$ & $2 \cdot 0$ & $2 \cdot 6^{*}$ & $2 \cdot 2^{*}$ & $1 \cdot 7^{*}$ & $1.8^{*}$ & $1 \cdot 1$ & $<0.001$ & 0.01 & 0.02 \\
\hline $18: 2 n-6 / 18: 3 n-3$ & $19 \cdot 0$ & $16 \cdot 1$ & $9 \cdot 6$ & $14 \cdot 4$ & $15 \cdot 2$ & $17 \cdot 5$ & $3 \cdot 3$ & $2 \cdot 5$ & $1 \cdot 8$ & 1.9 & 1.4 & $<0.001$ & $<0.001$ & 0.07 \\
\hline
\end{tabular}

d, Day.

a,bc Mean values for the LAR group with unlike superscript letters (for LSO group) were significantly different within a dietary group $(P<0.05)$.

${ }_{x, y, z}$ Mean values for the LSO group with unlike superscript letters were significantly different within a dietary group $(P<0.05)$.

${ }^{*}$ Mean values were significantly different between the two groups at the same age $(P<0.05)$.

† Significant difference between days 0 and 3 and between day 7 and days 21-32.

¥Significant difference between day 0 and days $3-32$. 
Table 5. Total lipid content and fatty acid composition of piglet brain at $0,3,7,21$ and $32 \mathrm{~d}$ of age in the linseed oil-based diet (LSO) and lard-based diet (LAR) groups (Mean values with their standard errors for four piglets)

\begin{tabular}{|c|c|c|c|c|c|c|c|c|c|c|c|c|c|c|}
\hline & \multicolumn{5}{|c|}{ LAR } & \multicolumn{5}{|c|}{ LSO } & \multirow[b]{2}{*}{ SEM } & \multicolumn{3}{|c|}{$P$} \\
\hline & do & d3 & $d 7$ & d21 & d32 & do & d3 & d7 & d21 & d32 & & Diet & Age & Diet $\times$ age \\
\hline \multicolumn{15}{|c|}{ Total lipid content ( $\mathrm{g} / 100 \mathrm{~g}$ of tissue) } \\
\hline & 5.4 & $5 \cdot 2$ & $6 \cdot 2$ & $6 \cdot 8$ & $7 \cdot 6$ & $5 \cdot 0$ & 5.5 & $6 \cdot 3$ & $7 \cdot 3$ & $7 \cdot 7$ & 1.3 & NS & $<0.001 \dagger$ & NS \\
\hline \multicolumn{15}{|c|}{ Fatty acid composition ( $\mathrm{g} / 100 \mathrm{~g}$ of total fatty acids) } \\
\hline SFA & $48 \cdot 3$ & 48.0 & 47.5 & $46 \cdot 9$ & $44 \cdot 7$ & $47 \cdot 7$ & $47 \cdot 2$ & $46 \cdot 4$ & $45 \cdot 0$ & $45 \cdot 0$ & $2 \cdot 2$ & NS & $<0.001 \ddagger$ & NS \\
\hline MUFA & $26 \cdot 0$ & $25 \cdot 2$ & $26 \cdot 3$ & 28.4 & 31.4 & $25 \cdot 6$ & 25.5 & $25 \cdot 3$ & $28 \cdot 2$ & 28.5 & $2 \cdot 9$ & NS & $<0.001 \S$ & NS \\
\hline PUFA & $25 \cdot 7$ & $26 \cdot 8$ & $26 \cdot 2$ & $24 \cdot 7$ & 23.9 & $26 \cdot 7$ & $27 \cdot 3$ & $28 \cdot 3$ & $26 \cdot 8$ & $26 \cdot 5$ & 1.8 & $<0.001$ & $<0.001 \|$ & NS \\
\hline$n-6$ PUFA & $12 \cdot 7$ & 13.9 & $14 \cdot 0$ & $13 \cdot 4$ & $12 \cdot 2$ & $12 \cdot 8$ & $13 \cdot 6$ & $14 \cdot 2$ & $12 \cdot 8$ & 12.5 & 1 & NS & $<0.0019$ & NS \\
\hline $18: 2 n-6$ & 0.6 & 1.6 & 1.7 & $2 \cdot 0$ & 1.6 & 0.5 & 1.7 & $2 \cdot 0$ & 2.4 & $2 \cdot 2$ & 0.7 & 0.02 & $<0.001^{\star \star}$ & NS \\
\hline $20: 4 n-6$ & $12 \cdot 1$ & $12 \cdot 2$ & $12 \cdot 3$ & 11.5 & $10 \cdot 7$ & $12 \cdot 3$ & 11.9 & $12 \cdot 1$ & 10.5 & 10.4 & $1 \cdot 1$ & NS & $<0.001 \dagger$ & NS \\
\hline$n-3$ PUFA & $12 \cdot 6^{a}$ & $12 \cdot 7^{\mathrm{a}}$ & $11.7^{\mathrm{b}}$ & $10 \cdot 8^{\mathrm{b}}$ & $11 \cdot 1^{\mathrm{b}}$ & 13.7 & $13 \cdot 6$ & $13.7^{\star}$ & $13 \cdot 6^{\star}$ & $13 \cdot 5^{\star}$ & 1.4 & $<0.001$ & 0.009 & 0.02 \\
\hline $18: 3 n-3$ & $0.7^{\mathrm{a}}$ & $0.8^{\mathrm{a}}$ & $0.9^{\mathrm{a}}$ & 1.0 & $1.5^{\mathrm{b}}$ & 0.8 & 0.8 & 0.8 & 1.1 & $0.9^{*}$ & 0.3 & 0.05 & $<0.001$ & 0.005 \\
\hline $20: 5 n-3$ & 0.5 & 0.5 & 0.4 & 0.4 & 0.4 & 0.5 & 0.5 & 0.4 & 0.4 & 0.4 & 0.1 & NS & NS & NS \\
\hline $22: 5 n-3$ & 0.4 & 0.5 & 0.5 & 0.5 & 0.5 & $0.5^{\mathrm{x}}$ & $0.7^{x}$ & $1 \cdot 1^{y *}$ & $1 \cdot 3^{\mathrm{z} *}$ & $1 \cdot 6^{z *}$ & 0.4 & $<0.001$ & $<0.001$ & $<0.001$ \\
\hline $22: 6 n-3$ & 11.0 & 11.0 & 10.0 & 8.7 & 8.8 & 11.9 & 11.6 & $11 \cdot 3$ & 10.9 & $10 \cdot 7$ & $1 \cdot 3$ & $<0.001$ & $<0.001 \dagger$ & NS \\
\hline$n-6$ PUFA $/ n-3$ PUFA & $1.0^{\mathrm{a}}$ & $1 \cdot 1^{\mathrm{a}}$ & $1 \cdot 2^{\mathrm{b}}$ & $1 \cdot 2^{\mathrm{b}}$ & $1 \cdot 1^{\mathrm{a}}$ & $0.9^{x}$ & $1.0^{y}$ & $1.0^{\mathrm{y} *}$ & $0.9^{\mathrm{x} *}$ & $0.9^{\mathrm{x} *}$ & 0.1 & $<0.001$ & 0.003 & 0.02 \\
\hline $18: 2 n-6 / 18: 3 n-3$ & 0.8 & 2.0 & 1.9 & 1.9 & 1.1 & 0.7 & $2 \cdot 1$ & $2 \cdot 7$ & $2 \cdot 3$ & $3 \cdot 2$ & $1 \cdot 3$ & 0.03 & 0.01 & 0.08 \\
\hline
\end{tabular}

d, Day.

Mean values for the LAR group with unlike superscript letters (for LSO group) were significantly different within a dietary group $(P<0.05)$.

${ }_{x, y, z}$ Mean values for the LSO group with unlike superscript letters were significantly different within a dietary group $(P<0.05)$.

* Mean values were significantly different between the two groups at the same age $(P<0.05)$.

† Significant difference between days 0 and 3 and day 7 and days $21-32$.

Significant difference between days 0 and 3 and between days $7-21$ and day 32 .

Significant difference between days $0-7$ and days $21-32$.

Significant difference between days $0-7$ and day 21 and day 32 .

१ Significant difference between day 0 and days $3-21$ and day 32 .

Significant difference between day 0 and days $3-32$. 
Table 6. Total lipid content and fatty acid composition of sow colostrum (day 0) and milk at 7, 14, 21 and $28 \mathrm{~d}$ after parturition in the linseed oil (LSO) and lard (LAR) groups (Mean values with their standard errors ( $(n)$ )

\begin{tabular}{|c|c|c|c|c|c|c|c|c|c|c|c|c|c|c|}
\hline & \multicolumn{5}{|c|}{ LAR } & \multicolumn{5}{|c|}{ LSO } & \multirow[b]{2}{*}{ SEM } & \multicolumn{3}{|c|}{$P$} \\
\hline & do & d7 & d14 & d21 & d28 & do & d7 & d14 & d21 & d28 & & Diet & Day & Diet $\times$ day \\
\hline \multicolumn{15}{|c|}{ Total lipid content ( $\mathrm{g} / 100 \mathrm{~g}$ of tissue) } \\
\hline & $5 \cdot 0$ & 9.0 & 7.5 & $7 \cdot 7$ & $7 \cdot 7$ & $5 \cdot 8$ & 8.5 & 8.6 & $9 \cdot 1$ & 7.9 & 1.7 & NS & $0.02 \dagger$ & NS \\
\hline \multicolumn{15}{|c|}{ Fatty acid composition ( $\mathrm{g} / 100 \mathrm{~g}$ of total fatty acids) } \\
\hline SFA & 31.5 & $37 \cdot 3$ & $50 \cdot 0$ & $40 \cdot 0$ & $42 \cdot 5$ & 27.5 & 35.9 & $40 \cdot 6$ & 34.3 & $39 \cdot 2$ & 8.6 & NS & NS & NS \\
\hline MUFA & $39 \cdot 0$ & $45 \cdot 2$ & $36 \cdot 0$ & 43.0 & $42 \cdot 3$ & $28 \cdot 3$ & 39.9 & 34.0 & 39.2 & 33.3 & $7 \cdot 3$ & 0.01 & NS & NS \\
\hline PUFA & 29.5 & 17.5 & 14.0 & $17 \cdot 0$ & $15 \cdot 2$ & 44.2 & 24.2 & 25.4 & 26.5 & 27.5 & $8 \cdot 7$ & $<0.001$ & $<0.001 \dagger$ & NS \\
\hline$n-6$ PUFA & $25 \cdot 7$ & $15 \cdot 1$ & $12 \cdot 1$ & $14 \cdot 8$ & $13 \cdot 2$ & 31.5 & $15 \cdot 1$ & $14 \cdot 3$ & $16 \cdot 2$ & 14.9 & 5.6 & 0.04 & $<0.001 \dagger$ & NS \\
\hline $18: 2 n-6$ & 24.3 & 14.4 & $11 \cdot 7$ & $14 \cdot 2$ & $12 \cdot 7$ & $30 \cdot 8$ & $14 \cdot 7$ & $14 \cdot 1$ & $15 \cdot 9$ & $14 \cdot 7$ & 5.5 & 0.01 & $<0.001 \dagger$ & NS \\
\hline $20: 4 n-6$ & 1.4 & 0.7 & 0.4 & 0.6 & 0.6 & 0.7 & 0.4 & 0.2 & 0.3 & 0.2 & 0.3 & $<0.001$ & $<0.001 \dagger$ & NS \\
\hline$n-3$ PUFA & 3.3 & $2 \cdot 0$ & 1.5 & 1.8 & 1.6 & $12 \cdot 4$ & 8.9 & $10 \cdot 8$ & $9 \cdot 9$ & $12 \cdot 3$ & 4.9 & $<0.001$ & NS & NS \\
\hline $18: 3 n-3$ & $2 \cdot 1$ & 1.3 & 1.0 & 1.3 & 1.2 & $10 \cdot 7$ & 8.0 & $10 \cdot 1$ & $9 \cdot 2$ & 11.6 & 4.7 & $<0.001$ & NS & NS \\
\hline $20: 5 n-3$ & 0.2 & 0.1 & 0.1 & 0.1 & 0.1 & 0.4 & 0.3 & 0.3 & 0.2 & 0.3 & 0.1 & $<0.001$ & NS & NS \\
\hline $22: 5 n-3$ & $0.5^{\mathrm{a}}$ & $0.3^{\mathrm{b}}$ & $0.2^{\mathrm{b}}$ & $0.2^{\mathrm{b}}$ & $0.2^{\mathrm{b}}$ & $0.8^{\mathrm{x*}}$ & $0 \cdot 3^{y}$ & $0 \cdot 2^{y}$ & $0.3^{y}$ & $0.2^{y}$ & 0.2 & $<0.001$ & $<0.001$ & 0.01 \\
\hline $22: 6 n-3$ & 0.1 & 0.1 & 0.1 & 0.1 & 0.1 & 0.2 & 0.1 & 0.1 & 0.1 & 0.1 & 0.1 & NS & $0.02 \dagger$ & NS \\
\hline$n-6$ PUFA/n-3 PUFA & 7.9 & $9 \cdot 6$ & 9.6 & $8 \cdot 2$ & 8.0 & $2 \cdot 6$ & 1.7 & 1.4 & 1.7 & 1.2 & 4.0 & $<0.001$ & NS & NS \\
\hline $18: 2 n-6 / 18: 3 n-3$ & 11.5 & 11.0 & 11.0 & $11 \cdot 2$ & $10 \cdot 7$ & 2.9 & 1.8 & 1.4 & $1 \cdot 7$ & 1.3 & $6 \cdot 2$ & $<0.001$ & NS & NS \\
\hline
\end{tabular}

d, Day.

a,b,c Mean values for the LAR group with unlike superscript letters (for LSO group) were significantly different within a dietary group $(P<0.05)$.

$x, y, z$ Mean values for the LSO group with unlike superscript letters were significantly different within a dietary group $(P<0.05)$.

*Mean values were significantly different between the two groups for the same day $(P<0.05)$.

† Significantly different between day 0 and days $7-28$. 
Table 5). There was a greater proportion of $n$-3 PUFA after day 7 in the LSO group than in the LAR group, with a decrease occurring from day 7 in the brain of the LAR piglets only (diet $\times$ age interaction $P=0 \cdot 02$; Table 5). The $18: 2 n-6$ to $18: 3 n-3$ ratio was greater in the brain of the LSO piglets than in that of the LAR piglets over the whole period (diet effect $P=0 \cdot 03$; Table 5).

The proportion of $18: 3 n-3$ increased between days 21 and 32 in the brain of the LAR piglets but not in that of the LSO piglets (diet $\times$ age interaction $P=0.005$; Table 5 ). There was no treatment effect on the proportion of $20: 5 n-3$ in the brain (Table 5). The proportion of $22: 5 n-3$ increased as of day 7 in the LSO group, and was greater in this group than in the LAR group from that age onwards (diet $\times$ age interaction $P<0.001$; Table 5). The proportion of $22: 6 n-3$ was greater in the brain of the LSO piglets than in that of the LAR piglets (diet effect $P<0.001$; Table 5). Although the diet $\times$ age interaction was NS $(P=0 \cdot 14), 22: 6 n-3$ proportion decreased in the LAR group from day 3 , while it remained constant over the whole period in the LSO group (age effect $P<0 \cdot 001$; Table 5). The proportion of $18: 2 n-6$ increased between days 0 and 3 in both the groups (age effect $P<0.001$ ), and it was greater overall in the LSO group (diet effect $P=0.02$; Table 5). The proportion of 20:4n-6 decreased between days 7 and 21 in both the groups (age effect $P<0 \cdot 001$; Table 5).

\section{Discussion}

The high contents of $n$-3 LC-PUFA in the placenta suggest that sows are capable of synthesising $n$-3 LC-PUFA from dietary 18:3n-3 during gestation, although the site of synthesis is not known. The capacity of adults to convert $18: 3 n-3$ to $20: 5 n-3$ or $22: 6 n-3$ is very limited ${ }^{(8,9)}$, but this synthesis seems to increase during gestation ${ }^{(10,11)}$. Indeed, Brazle et $a l .{ }^{(21)}$ reported an increase in $n$-3 LC-PUFA in the placenta of sows fed 18:3n-3-rich diet during gestation, suggesting the synthesis of $n$-3 LC-PUFA from dietary $18: 3 n-3$ also. Moreover, Otto et al. ${ }^{(10)}$ showed that the percentage of $22: 6 n-3$ in plasma phospholipids from women increased in early pregnancy $(2.98 \%$ at 4 weeks of pregnancy v. $3.93 \%$ at 10 weeks of pregnancy) without modification in the dietary intake. In the present study, LSO in the maternal diet increased LC-PUFA accumulation in the placenta. Placental transfer of certain fatty acids (octanoic acid, palmitic acid and linoleic acid) has been reported to be quite limited in sows $^{(22,23)}$ whose placenta is epitheliochorial ${ }^{(22)}$. However, Rooke et al. ${ }^{(14,24)}$ observed that supplementation of the sow diet with $n$-3 LC-PUFA during gestation increased the percentages of $20: 5 n-3$ and $22: 6 n-3$ in piglet cord plasma at birth. Although specific measurements of the placenta were not performed, it can be suggested that $n$-3 LC-PUFA cross the sow placenta during gestation, similar to what is observed in human subjects, where $n$ - 3 LC-PUFA are transferred from the mother to the foetus by a specific transporter called plasma membrane fatty acid-binding protein ${ }^{(25,26)}$. In addition, a recent study has demonstrated that supplementing the sow diet with $18: 3 n-3$ from vegetable sources or with $n$-3 LC-PUFA from marine sources during early gestation affects the fatty acid composition of the placenta and the foetus at $40 \mathrm{~d}$ of gestation. This is consistent with the idea of placental transport of $n$-3 LC-PUFA between the sow and foetuses $^{(21)}$. Whether this increase in LC-PUFA in placental tissue in the present study is related to an upregulation of fatty acid transporters in this tissue needs further investigations.

The fatty acid composition of piglet tissues before suckling was influenced by the maternal diet. At birth, the carcasses of piglets from the LSO sows had greater proportions of $n-3$ LC-PUFA than the carcasses of piglets from the LAR sows, whereas in the plasma, the proportions of $20: 5 n-3$ and $22: 6 n-3$, but not of $22: 5 n-3$, were greater with the LSO diet. Although the elongation and desaturation enzymes for LC-PUFA synthesis are present in the fetal liver of piglets $^{(27,28)}$, their activity appears to be low before birth than in the postnatal period ${ }^{(27,28)}$, suggesting that the $n-3$ LC-PUFA accumulated by the foetus in utero are derived predominantly from placental transfer. The dietary maternal $18: 3 n-3$ content seems to be important for the deposition of $n$-3 LC-PUFA in fetal tissues. Indeed, Rooke et al. ${ }^{(14)}$ demonstrated that inclusion of $26 \mathrm{~g} / \mathrm{d}$ of LSO in the diet of sows during gestation increased the proportion of $20: 5 n-3$ (1.4 times more than control) and 22:6n-3 (1.2 times more than control) in the plasma of piglets at birth compared with piglets born to sows without dietary LSO supplementation. In the present study, sows were fed $42 \mathrm{~g} / \mathrm{d}$ of LSO, which increased the proportion of $20: 5 n-3$ by 2.4 times and of $22: 6 n-3$ by 1.7 times in the plasma of the LSO piglets compared with the LAR piglets at birth. However, we have recently observed that supplementation of $105 \mathrm{~g} / \mathrm{d}$ of LSO in the diet of sows during gestation increased the proportion of $20: 5 n-3(5 \cdot 2$ times more than control) and $22: 6 n-3(1 \cdot 35$ times more than control) in erythrocytes of piglets at birth compared with piglets from sows receiving no LSO (Boudry $\mathrm{G}$, personal communication). In the last study, the lower synthesis of $22: 6 n-3$ compared with the present study might be due to the enzymatic competition between $n-3$ PUFA for the $\Delta-6$ desaturase. Indeed, this enzyme is involved in two steps during the $n-3$ LC-PUFA synthesis pathway, namely in the first step to convert $18: 3 n-3$ into $20: 5 n-3$, and in the second step to convert $22: 5 n-3$ into $22: 6 n-3$. An excessive level of $18: 3 n-3$ in the liver could therefore inhibit the synthesis of $22: 6 n-3$ from $22: 5 n-3$, suggesting that the maternal diet has to be supplemented with an optimal content of $18: 3 n-3$ to allow the synthesis of all $n-3$ LC-PUFA which will be transferred to the foetus. In the piglet brain at birth, the proportion of $22: 6 n-3$ tended to be greater with the LSO diet. This high level of $22: 6 n-3$ in the LAR piglet brain despite the relatively low level of $18: 3 n-3$ in the sow diet during gestation is consistent with the fact that during foetal development, the brain is a preferential tissue to accumulate $22: 6 n-3$. Therefore, increasing the dietary level of $n$-3 PUFA has only little impact on brain $22: 6 n-3$ proportion.

Our results on milk and fatty acid composition are consistent with those reported by Farmer \& Petit ${ }^{(13)}$ who showed that $18: 3 n$-3-rich diet during gestation and lactation increased the percentages of $20: 5 n-3$ and $22: 5 n-3$ in sow milk on days 3 and 20 of lactation with no difference for $22: 6 n-3$. In the present study, the milk of the LSO sows had greater proportions of $18: 3 n-3$ compared with the other $n-3$ LC-PUFA. The relative contents of $n-3$ PUFA in milk reflect the nutritional status of mothers during gestation and lactation. 
Similar results were reported for several species, including human subjects ${ }^{(29,30)}$, rats $^{(31)}$ and sows ${ }^{(1,12,32)}$. Moreover, Rodriguez-Cruz et al. ${ }^{(33)}$ demonstrated that the $\Delta-6$ desaturase was present in lactating mammary gland of rats, which could explain, if similar in sows, why sows in the present study had milk that was richer in LC-PUFA.

The maternal LSO diet influenced the fatty acid composition of piglet tissues during the postnatal life. Piglets suckling the LSO sows consumed high levels of $18: 3 n-3$ through the milk. This resulted in the increased plasma and carcass proportions of $18: 3 n-3,20: 5 n-3$ and $22: 5 n-3$, with the proportion of $18: 3 n-3$ in the plasma and carcasses of LSO piglets increasing with time. Assuming that the carcass weight to live weight of piglets and the fatty acid content to total lipid content ratio are constant during the postnatal period, we estimated that the total amount of fatty acid deposit in the carcasses of piglets increases from birth to day 32 $(0 \cdot 1-2 \cdot 3 \mathrm{~g}$ for $20: 5 n-3 ; 0 \cdot 3-4 \cdot 1 \mathrm{~g}$ for $22: 5 n-3$ and $0.5-1.4 \mathrm{~g}$ for $22: 6 n-3)$. This suggests that piglets efficiently absorbed $18: 3 n-3$ derived from the maternal milk, and were capable of transforming it to $n$-3 LC-PUFA during the postnatal period.

The evolution of fatty acid composition in piglet brain was different from that of fatty acid composition in piglet plasma and carcasses. Although not different during the first week after birth, the proportion of $22: 5 n-3$ and $22: 6 n-3$ were greater from day 7 in the brain of the LSO piglets than in that of the LAR piglets, with no difference for $18: 3 n-3$ and $20: 5 n-3$. The $22: 6 n-3$ could, in part, be transported via the circulation from the carcass to the brain. Furthermore, the neonatal piglets might be capable of synthesising $22: 6 n-3$ from $22: 5 n-3$ in the brain during the postnatal life. Indeed, Clandinin et al. ${ }^{(28)}$ demonstrated that the enzymatic activities that are necessary to synthesise LC-PUFA in the brain of piglets double between the foetal and the postnatal period.

In conclusion, LSO in the maternal diet during gestation and lactation increases LC-PUFA content in the placenta and $22: 6 n-3$ deposition in the carcasses and brain of piglets at birth. Furthermore, this diet maintains the proportion of $22: 6 n-3$ in the brain of the LSO piglets compared with the LAR piglets during the postnatal period. However, although LSO could be an interesting alternative source of $n-3$ PUFA for women, caution should be exercised while using LSO in diets. This oil is easily oxidised and, consequently, must be supplemented with antioxidants and/or an adequate protein level in the $\operatorname{diet}^{(34)}$. Moreover, the present work raises questions on the optimal dose of LSO, which seems to be a key component to modulate sow and piglet fatty acid metabolism and tissue composition. Further work is also needed to understand the dietary regulation of fatty acid transporters in the placenta, and to explore the capacity of neonatal piglets to transform maternal $18: 3 n-3$ in $n-3$ LC-PUFA, especially in the brain.

\section{Acknowledgements}

G. B. and J. M. designed all the experiments; F. d. Q. conducted the experiment and analysed the data; and F. d. Q. and G. B. wrote the draft of the manuscript; all the authors critically reviewed the manuscript. The authors would like to thank Cécile Perrier, Martine Fillaut, Gwennola Robin,
Daniel Boutin, Yannick Surel and Henri Renoult for laboratory analyses and technical help. The authors disclose that there is no conflict of interest.

\section{References}

1. Gerfault V, Mourot J, Etienne M, et al. (1999) Influence de la nature des lipides dans le régime de gestation de la truie sur ses performances et la composition corporelle des porcelets à la naissance (Influence of the nature of lipids in gestation diet on sow performance and body composition of piglets at birth). Journées Rech Porcine en France 31, 191-197.

2. Lapillonne A (2007) Acides gras Oméga-3 et Oméga-6 au cours de la grossesse et de la petite enfance (Omega-3 and omega-6 fatty acids during pregnancy and early childhood). Cah Nutr Diét 42, 38-42.

3. Voss A, Reinhart M, Sankarappa S, et al. (1991) The metabolism of $7,10,13,16,19$-docosapentaenoic acid to $4,7,10$, 13, 16, 19-docosahexaenoic acid in rat liver is independent of a 4-desaturase. J Biol Chem 266, 19995-20000.

4. Legrand $P$ (2007) Les acides gras: structures, fonctions, apports nutritionnels conseillés (Fatty acids: structures, functions, recommended dietary intake). Cah Nutr Diét 42, 7-12.

5. Neuringer M, Connor WE, Van Petten C, et al. (1984) Dietary omega-3 fatty acid deficiency and visual loss in infant rhesus monkeys. J Clin Invest 73, 272-276.

6. Reichardt P, Müller D, Posselt U, et al. (2004) Fatty acids in colostrum from mothers of children at high risk of atopy in relation to clinical and laboratory signs of allergy in the first year of life. Allergy 59, 394-400.

7. Ailhaud G, Massiera F, Weill P, et al. (2006) Temporal changes in dietary fats: role of $n-6$ PUFA in excessive adipose tissue development and relationship to obesity. Prog Lipid Res 45, 203-236.

8. Mantzioris E, James MJ, Gibson RA, et al. (1993) Dietary substitution with an $\alpha$-linolenic acid-rich vegetable oil increases eicosapentaenoic acid concentrations in tissues. Am J Clin Nutr 59, 1304-1309.

9. Burdge GC \& Wootton SA (2002) Conversion of $\alpha$-linolenic acid to eicosapentaenoic, docosapentaenoic and docosahexenoic acids in young women. Br J Nutr $\mathbf{8 8}, 411-420$.

10. Otto SJ, van Houwelingen AC, Badart-Smook A, et al. (2001) Changes in the maternal essential fatty acid profile during early pregnancy and the relation of the profile to diet. Am J Clin Nutr 73, 302-307.

11. Bakewell L, Burdge GC \& Calder PC (2006) Polyunsaturated fatty acid concentrations in young men and women consuming their habitual diets. Br J Nutr 96, 93-99.

12. Bazinet RP, McMillan EG \& Cunnane SC (2003) Dietary $\alpha$-linolenic acid increases the $n$-3 PUFA content of sow's milk and the tissues of the suckling piglet. Lipids 38, $1045-1049$.

13. Farmer C \& Petit HV (2009) Effects of dietary supplementation with different forms of flax in late-gestation and lactation on fatty acid profiles in sows and their piglets. J Anim Sci 87, 2600-2613.

14. Rooke JA, Shanks M \& Edwards SA (2000) Effect of offering maize, linseed or tuna oils throughout pregnancy and lactation on sow and piglet tissue composition and piglet performance. Anim Sci 71, 289-299.

15. de Groot RHM, Hornstra G, van Houwelingen AC, et al. (2004) Effect of $\alpha$-linolenic acid supplementation during pregnancy on maternal and neonatal polyunsaturated fatty acid status and pregnancy outcome. Am J Clin Nutr 79, 251-260. 
16. Noblet J, Dourmad JY \& Etienne M (1990) Energy utilization in pregnant and lactating sows: modeling of energy requirements. J Anim Sci 68, 562-572.

17. Folch J, Lees M \& Stanley GHS (1957) A simple method for the isolation and purification of total lipids from animal tissues. J Biol Chem 226, 497-509.

18. Jensen RG \& Clark RM (1984) Methods of lipid analysis. J Pediatr Gastroenterol Nutr 3, 296-299.

19. Hamilton JG \& Comai K (1988) Separation of neutral lipid, free fatty acid and phospholipid classes by normal phase HPLC. Lipids 23, 1150-1153.

20. Morrisson WR \& Smith LM (1964) Preparation of fatty acid methyl esters and dimethyl acetals from lipids with boron fluoride-methanol. J Lipid Res 5, 600-608.

21. Brazle AE, Johnson BJ, Webel SK, et al. (2008) Omega-3 fatty acids in the gravid pig uterus as affected by maternal supplementation with omega-3 fatty acids. J Anim Sci 87, 994-1002.

22. Thulin AJ, Allee GL, Harmon DL, et al. (1988) Utero-placental transfer of octanoic, palmitic and linileic acids during late gestation in gilts. J Anim Sci 67, 738-745.

23. Ramsay TG, Karousis J, White ME, et al. (1991) Fatty acid metabolism by the porcine placenta. J Anim Sci 69, 3645-3654.

24. Rooke JA, Sinclair AG \& Ewen M (2001) Changes in piglet tissue composition at birth in response to increasing maternal intake of long-chain $n-3$ polyunsaturated fatty acids are nonlinear. Br J Nutr 86, 461-470.

25. Haggarty P (2004) Effect of placental function on fatty acid requirements during pregnancy. Eur J Clin Nutr 58, 1559-1570.
26. Glatz JFC \& van der Vusse J (1996) Cellular fatty acid binding proteins: their function and physiological significance. Prog Lipid Res 35, 243-282.

27. Clandinin MT, Chappell JE, Heim T, et al. (1981) Fatty acid utilization in perinatal de novo synthesis of tissues. Early Hum Dev 5, 355-366.

28. Clandinin MT, Wong K \& Hacker RR (1984) Synthesis of chain elongation-desaturation products of linoleic acid by liver and brain microsomes during development of the pig. Biochem $J$ 226, 305-309.

29. François CA, Connor SL, Bolewicz LC, et al. (2003) Supplementing lactating women with flaxseed oil does not increase docosahexaenoic acid in their milk. Am J Clin Nutr 77, 226-233.

30. Fidler N, Sauerwald T, Pohl A, et al. (2000) Docosahexaenoic acid transfer into human milk after dietary supplementation: a randomized clinical trial. J Lipid Res 41, 1376-1383.

31. Yeh YY, Winters BL \& Yeh SM (1990) Enrichment of (n-3) fatty acids of suckling rats by maternal dietary menhaden oil. J Nutr 120, 436-443.

32. Fritsche KL, Huang SC \& Cassity NA (1993) Enrichment of omega-3 fatty acids in suckling pigs by maternal dietary fish oil supplementation. J Anim Sci 71, 1841-1847.

33. Rodriguez-Cruz M, Tovar AR, Palacios-Gonzalez B, et al. (2006) Synthesis of long-chain polyunsaturated fatty acids in lactating mammary gland: role of delta5 and delta6 desaturases, SREBP-1, PPARalpha, and PGC-1. J Lipid Res 47, 553-560.

34. Rao SS, Kale AA, Joshi SR, et al. (2007) Sensitivity of fetus and pups to excess levels of maternal intakes of alpha linolenic acid at marginal protein levels in Wistar rats. Reprod Toxicol 24, 333-342. 